\title{
Intergenerational and Socioeconomic Gradients of Child Obesity*
}




\begin{abstract}
Can the rise in obesity among children be attributed to intergenerationally parental influences? Does it affect the influence of parent's socioeconomic status on obesity? This paper documents evidence of an emerging social gradient of obesity in pre-school children resulting from a combination of both socio-economic status and less intensive childcare associated with maternal employment, when different forms of intergenerational transmission are controlled for. We also estimate and decompose income related inequalities in child obesity. The study takes advantage of a uniquely constructed dataset from Spain spanning the years 2003 to 2006, a period in which a significant spike in the growth of child obesity was observed. Our results suggest robust evidence of a socioeconomic and intergenerational gradient. Higher income systematically explains obesity in children and inequalities in child obesity have doubled in just three years with a pure income effect accounting for as much as $72-66 \%$ of these income inequality estimates, even when intergenerational transmission is accounted for. Although, intergenerational transmission does not appear to be gender specific, when accounted for, mother's labour market participation only explains obesity among boys but not among girls.
\end{abstract}

Keywords: child obesity, intergenerational transmission, socio-economic gradient, inequalities in child health.

JEL Classification: I12, I19, D13. 


\section{Introduction}

The prevalence of obesity among children is rising at alarming rates. Latest estimates from the International Association for the Study of Obesity (IASO, 2011) suggest that overweight (including obesity) among children aged 5 to 17 years in Spain (33\% among boys and 23\% among girls) is, together with Greece, Italy and, the UK, among the highest in Europe. Such estimates are especially concerning given its impact on a child's burden of disease in childhood, adolescence and adulthood (Berenson et al., 1993; Hoffmans et al., 1988; Wright, 2001), and its impact later marriage and income (Gortmaker, 1993; Sargent and Blanchflower, 1994). Adolescents that suffer from obesity are more likely to attempt suicide (Eisenberg et al., 2003) and to perform worse at school (Schwimmer et al., 2003).

Socioeconomic status is often found to be inversely associated with child and adolescent obesity as measured by high levels of BMI (Goodman, 1999; Gordon-Larsen et al., 2003; Wang and Zhang, 2006, Case et al., 2002). In addition, Case et al. (2008), using expanded English and US samples, showed that the income-health gradient for children does indeed increase with age in both countries. Importantly, some evidence suggesting an association between child obesity and female employment which is more intense among poorer people (von Hinke Kessler Scholder, 2008). ${ }^{1}$ One potential source might lie in the intergenerational transmission process itself (Baum II and Ruhm, 2007). ${ }^{2}$

Unlike obesity in adults, obesity in children is heavily influenced by both parents choice of lifestyles and the overall child's social environment in addition to genetic transmission (Anderson et al, 2009; Emanuel et al. 1992). Early studies such as Coate (1983) already reveal that the probability of an adolescent (10-16) being obese increases by $20 \%$ if either of his parents is obese. However, with few exceptions, intergenerational transmission is not generally accounted for in studies looking at socio-economic determinants of child obesity. Exceptions include Goode et al. (2008) who find that the intergenerational transmission of unhealthy eating habits appears to be more intense amongst individuals in low income households. Currie and Moretti (2007), drawing upon birth records from California, find evidence of a substantial intergenerational correlation as well as an intergenerational transmission of low birth weight, which appears to be stronger for individuals of low socioeconomic status. Propper et al. (2007) find that a mother in the top quantile of the prepregnancy BMI is $15 \%$ more likely to have a child with a BMI distribution in the top $10 \%$. 
Khanam et al. (2009) found that maternal health plays an intermediary role so that the socioeconomic gradient in child health disappears when parental health is controlled for. In contrast, Anderson et al. (2009) not only report that obesity rates are $25 \%$ higher for disadvantaged children but also find that these children gained weight faster. However, importantly, parent-child elasticity and identifiable environmental factors did not exhibit much difference. ${ }^{3}$ Based on this evidence we can conclude that socioeconomic and intergenenrational gradients do interact, yet how such an interaction plays out is still inconclusive.

This paper seeks to contribute to the literature by examining the influence of the intergenerational transmission of obesity and its effects on the socioeconomic gradient of obesity. After netting out this influence, we then estimate and decompose the income-related inequalities in child and adolescent obesity. This paper forwards the hypothesis of socioeconomic gradients in child obesity as being more acute among children in lower socioeconomic households after intergenerational transmission is accounted for, and hence whether it furthers the income gradient in children's health. We rely on unique data from one country (Spain) over two points in time where we observe a sharp increase in child obesity. It is our contention that this strategy should allow us to disentangle the extent to which the rise in childhood obesity, and its underpinning socioeconomic gradient, result from a specific combination of parental obesity, tighter budget restrictions, education and maternal employment. Secondly, the paper contributes by examining the socioeconomic gradients of obesity and overweight in children. We have estimated the concentration index, the income elasticities and factor decomposition between 2003 and 2006 before and after controlling for the transmission of obesity and overweight.

Our results suggest evidence of a socioeconomic gradient in child obesity that is robust to the controls for the intergenerational transmission of life styles, and the effect of the intergenerational transmission tends to concentrate in the extreme income quantiles. Mother's labour market participation significantly explains obesity among boys but not among girls. Finally, we find that income inequalities in child obesity have doubled in just three years with a pure income effect accounting for between $72-66 \%$ of these income inequality estimates. In section 2 we report existing evidence and background. Section 3 highlights the empirical methods employed, section 4 and 5 are devoted to data and results and section 6 concludes. 


\section{Intergenerational and Socioeconomic Obesity Gradients}

\subsection{Pure Intergenerational Gradients}

Parents can influence their children's weight both directly through their genetic influence and environmentally, given that parents' food choices are learned by their children and are so repeated over time. Goode et al. (2008) finds using Scottish data that the paternal history of eating habits has no impact on either sons or daughters while the maternal history influences negatively the eating behaviour of daughters.

The medical literature refers to the correlations of "child to adult body mass" effects (Lake et al., 1997, Whitaker et al., 1997). Ahlburg (1998) reports estimates of intergenerational correlations for life spans between parents and children in the range of 0.150.3. Classen and Hokayem (2005) find that children of extremely obese mothers (with BMI greater than 40) are 50\% more likely to be obese than their counterparts with mothers having BMI levels in the recommended range of $18.5-25 \mathrm{~kg} / \mathrm{m}^{2}$. Similarly, Classen (2010) finds an intergenerational correlation of BMI between female children and their mothers of 0.38 relative to a BMI correlation of 0.32 between mothers and their sons, and children of obese mothers are found to be $38 \%$ more likely to be overweight or obese. Monherit et al. (2009) finds evidence of parental body weight influencing adolescents' body weight. This result contrasts with an earlier study by Coate (1983) showing that while parental obesity does influence child and adolescent weight, diet is unrelated to these outcomes so only genetic transmission matters. By contrast, Anderson et al. (2003) finds that a mother's BMI is strongly related to child overweight. However, how do such important intergenerational effects influence the socio-economic gradient in child obesity?

\subsection{Socioeconomic and Intergenerational Gradients}

A long-lasting literature (Case et al., 2004, Currie et al., 2004, Currie and Stabile, 2003, Currie and Hyson, 1999; Case et al., 2008) has documented a family income gradient in child health. However, its interpretation is controversial (Abernathy et al., 2002). One explanation lies in that socially disadvantaged individuals are found to have less autonomy to choose healthy behaviours (Wickrama et al., 1999). More specifically, as applicable to child obesity there is some evidence that indicates evidence of pro-rich socio-economic inequalities (Kinra 
et al., 2000; Armstrong et al., 2003) intermediated by parent's education influences as well as mother employment (Anderson et al., 2003, Cawley and Liu 2007), parental control of adolescent diets does exert an influence on adult obesity (Crossman et al., 2006) as well as other unobserved parental factors (Dooley and Stewart, 2007).

Finally, Anderson et al. (2009) finds that the intergenerational BMI elasticity between women and their children has increased from 1971 to 2004, but that importantly it does not vary significantly between families of different income levels when intergenerational gradient is accounted for.

\section{Methods}

\subsection{Measurement of childhood obesity}

We measure childhood obesity by means of parents' self-reported data on height and weight allowing us to define the "body mass index" (BMI) indicator as weight in kilograms divided by the square of height in meters. Given the difficulties of straight BMI as a measure of adiposity among children, we use in addition age and gender specific reference cut-off points to measure child obesity. More specifically, we follow two alternative methods to measure childhood obesity. First, we rely BMI cut-off points corresponding to the $97^{\text {th }}\left(85^{\text {th }}\right)$ centile for obesity (overweight) as in Sobradillo et al. (2002) also known as 'Orbegozo Foundation' tables. Second, we also employ "international" cut-off points as in Cole et al. (2000). Following the recommendations of the International Obesity Task Force (IOTF), these authors were able to calculate BMI cut-off points for children aged 2-18 years by using data from six countries and the centile based method.

\subsection{Empirical methods: determinants of childhood obesity}

We first examine the prevalence of childhood obesity for a representative sample of Spanish children by estimating a probit regression model. We are interested in the probability of a child becoming obese $\left(y^{*}\right)$ satisfying the linear model:

$$
y^{*}=X^{\prime} \beta+u
$$


where $y^{*}$ is the underlying unobserved (or latent) continuous variable, $\mathrm{X}$ is a set of regressors, $\beta$ is a vector of unknown parameters and $u$ the error term. Yet, what we observe and estimate is the outcome variable, $y$, taking one of two values:

$$
y= \begin{cases}1 & \text { if } y^{*}>0 \\ 0 & \text { if } y^{*} \leq 0\end{cases}
$$

Thus the conditional probability of child obesity takes the form:

$$
\operatorname{Pr}(y=1 \mid X)=\operatorname{Pr}\left(y^{*}>0\right)=\operatorname{Pr}\left(X^{\prime} \beta+u>0\right)=\operatorname{Pr}\left(-u<X^{\prime} \beta\right)=\Phi\left(X^{\prime} \beta\right)
$$

where $\Phi\left(X^{\prime} \beta \mid X_{k}=1\right)$ is the standard normal cumulative distribution function for the error term $u \approx N(0,1)$, giving rise to the probit model. The maximum likelihood (ML) estimator is used to estimate the set of $\beta$ coefficients. As these probit coefficients cannot be given a direct quantitative interpretation we need to compute marginal (average) effects for the continuous (binary) explanatory variables. As a robustness check we further estimated through OLS and quantile regression the influence of the same set of explanatory variables on the (continuous) child body mass index, so as to measure whether the effects of the main set of covariates remained valid.

Up to this point, the above estimations seek to analyse the empirical association between childhood and parental obesity but they overlook the key issue of endogenity of parental obesity status. However, as is well known, probit ML estimators are inconsistent if any of the regressors are endogenous. To overcome this problem we adjusted a generalised version of the bivariate probit model in order i) to allow for the correlation between the error terms of the child and parental obesity equations and to recognise the existence of unobservable individual characteristics affecting both outcomes and ii) to accommodate the endogenous effect of the parental obesity covariate. Specifically, we specify a joint model for two unobserved latent variables $\left(y_{1}^{*}\right.$ : childhood obesity; $y_{2}^{*}$ : parental obesity) that may be correlated and depend linearly on a set of explanatory variables as, 


$$
\begin{aligned}
& y_{1}^{*}=\delta_{1} y_{2}^{*}+X_{1}^{\prime} \beta_{1}+\varepsilon_{1} \\
& y_{2}^{*}=X_{1}^{\prime} \pi_{1}+Z_{2}^{\prime} \pi_{2}+\varepsilon_{2}
\end{aligned}
$$

where the first equation is the structural equation of interest and the second equation is the reduced form of the endogenous discrete regressor $y_{2}$ (parental obesity). Here the errors $\varepsilon_{1}$ and $\varepsilon_{2}$ are jointly normally distributed with means of 0 and variances of 1 , and correlations of $\rho$. In this model the two observed binary outcomes are,

$$
y_{1}=\left\{\begin{array}{ll}
1 & \text { if } y_{1}^{*}>0 \\
0 & \text { if } y_{2}^{*} \leq 0
\end{array} \text { and } y_{2}= \begin{cases}1 & \text { if } y_{2}^{*}>0 \\
0 & \text { if } y_{2}^{*} \leq 0\end{cases}\right.
$$

the model collapses to two separate probit models for $y_{1}$ and $y_{2}$ if $\rho=0$. Interestingly, notice that in equation (4) $X_{1}$ is a vector of exogenous regressors and $Z_{2}$ is a vector of additional instruments that affect $y_{2}$ or parental obesity but that they can be excluded from the structural equation as they do not directly affect childhood obesity $\left(y_{1}\right)$. The reduced equation serves as a source of identifying instruments and these excluded instruments are essential for identifying the parameters of the structural equation.

\subsection{A note on the instruments selected}

We assume parental obesity to be an endogenous regressor. The intuitive justification lies in the fact that there would appear to be various mechanisms, both cultural and genetic, that might explain the transmission of obesity. Bearing in mind the difficulty of deriving good instruments, we constructed three potential instruments for parental obesity intended to reflect the actual living conditions of the child's father/mother during his/her childhood and more generally of Spanish society at that time. Thus, the goal was to capture a wealth effect when the mother/father was 10 years old. Hence, the lpmilk10 instrument is the log of the annual production of milk (in litres per capita) in the year in which the mother was aged 10, the lgdppc10 instrument is measured as the log of the GDP per capita (in real 1995 PTA) when the mother was aged 10 and, finally, lpbeef10 instrument is the log of the annual production of beef when the mother was aged 10. These instruments are likely to be relevant since each is expected to present a significant negative correlation with parental obesity $\left(y_{2}\right)$. Generally 
speaking, the better the economic conditions (proxied by these instruments) enjoyed by the population, the lower is the expected obesity prevalence rate. In addition, to be valid, the instruments must satisfy $E\left(\varepsilon_{1} \mid Z_{2}\right)=0$. In practice, we opted to estimate an exactly identified model where the number of exogenous regressors equals the number of instruments.

\subsection{The income-related inequalities in child obesity}

To estimate the income-related inequalities in child obesity we followed the traditional procedures based on the calculation of concentration indices. Specifically, this index is calculated using the "convenient regression" approach proposed by Kakwani et al. (1997). We further decomposed these concentration indices, along the lines suggested by Wagstaff et al. (2003), according to the individual factors that contribute to income-related inequalities in child obesity. For any linear additive regression model of child obesity $(y)$ on a set of regressor $(x)$ such as,

$$
y=x^{\prime} \beta+\varepsilon
$$

the concentration index for $y(\mathrm{CI})$ can be decomposed as follows,

$$
C I=\sum_{k}\left(\beta_{k} \bar{x}_{k} / \mu\right) C_{k}+G C_{\varepsilon} / \mu
$$

where $\mu$ is the mean of $y, \bar{x}_{k}$ is the mean of $x_{k}, C_{k}$ is the concentration index of the regressor $k$ and $G C_{\varepsilon}$ is the generalised concentration index for the error term. Equation 7 highlights that the CI of child obesity is equal to a weighted sum of the concentration indices of the set of regressors, where the weight for $x_{k}$ is the elasticity of $y$ respect to $x_{k}$ $\left(\eta_{k}=\beta_{k} \frac{\bar{x}_{k}}{\mu}\right)$, plus a residual component.

\section{Data}

We used pooled data from the 2003-04 and 2006-07 editions of the Spanish National Health Survey (SNHS). This is a biannual and nationwide cross-section survey collecting 
information on a wide array of health variables including anthropometrical characteristics and socio-economic status of individuals. Both surveys contain separate adult (16+) and child samples in addition to a household questionnaire. This study is based on the child sample and where required we match information gathered from the adult and household samples.

The original pooled sample contained 15,231 observations of children aged 0-15 from all Spanish regions. Notice the dataset has a non-negligible share of missing information on children's weight and height measurements. Fortunately, rather than deleting these observations (concentrated mainly at the younger ages), we took advantage of a survey question (with almost no missing information) intended to elicit the relationship between a child's height and weight. This allowed us to impute average weight and height based on nonmissing cases for this subset of children. Abnormally high and low BMI values were excluded from the estimations. In addition, some observations were excluded owing to missing parental information (i.e. household income, weight and height) and individuals being below the age of two. As a result, our pooled sample contained 13,358 observations of children aged 2-15 (5,483 for the sample $2003-04 ; 7,875$ for the sample 2006-007).

Table 1 presents the definition of the variables used in the regressions. In the case of the dependent variables, we measured child overweight and obesity as binary indicators taking into account both the Orbegozo Foundation and the IOTF cut-off points. Moreover, we also used a continuous covariate to measure child BMI. As for the independent variables, we classified the covariates in four groups: a) children's variables including information on gender, age, physical activity in leisure time, Mediterranean diet, watching TV on a daily basis and number of hours slept per day; b) parents' socio-economic controls including income, education and mother's labour participation; c) key controls for parents such as the adult obesity rate or adult BMI; and d) parents' civil status and sample year. Notwithstanding, given the type of information collected in the adult questionnaire, adult obesity or BMI refers here to the presence of such condition in the father or in the mother.

\section{[Insert Table 1 about here]}

As the survey collects household income in intervals (with up to eight responses) an interval regression was run to estimate an income level for each household. Additionally, we imputed 
a (log) net household income in equivalent terms to each child to account for within household's economies of scale. As for the parental level of education we distinguished up to three levels of completed education: primary or less than primary education, secondary education (the omitted category) and university education.

To verify empirically the veracity of our hypothesis regarding the vertical transmission of obesity, we analysed the influence of the adult obesity rate (BMI) as a key determinant of parental lifestyles and, consequently, as a problem of agency failure. We expected to find a positive effect of this key control on the children's obesity (BMI) equation. As discussed above, parent's increasing income and education are expected to reduce the probability of childhood obesity (BMI). To test the possible association between the mother's labour participation and the prevalence of childhood obesity (BMI) we defined a binary variable measuring whether the mother participates actively in the labour market (i.e., being employed or unemployed). In principle, a positive relationship is expected between the number of hours devoted by the mother to work (resulting in less intensive childcare) and child obesity or BMI.

\section{Results}

\subsection{Preliminary Evidence}

Table 1 shows that the mean BMI of the children aged 2-15 in our pooled data set is 18.22 $\mathrm{kg} / \mathrm{m}^{2}$. The mean BMI of boys (girls) increases from $16.58(15.83) \mathrm{kg} / \mathrm{m}^{2}$ at age 2 to 20.99 (20.45) $\mathrm{kg} / \mathrm{m}^{2}$ at age 15 . This pattern of mean BMI is roughly similar to that reported by Serra et al (2003) using another dataset based on clinical measurements. According to the 'Orbegozo F.' reference tables the prevalence of overweight for both genders is $23.3 \%$ (defined at the $85^{\text {th }}$ percentile) while the obesity rate is $12.6 \%$ (defined at the $97^{\text {th }}$ percentile). Interestingly, a number of differentials are found when the IOTF tables are applied. Thus, childhood overweight is significantly higher $(28.6 \%)$ while childhood obesity is lower $(9.5 \%)$. As in other western countries, childhood obesity has accelerated in Spain at all ages in the last two decades.

The intuition that the prevalence of childhood obesity is not linearly distributed by age is captured in Figure 1. An inverted U-shape distribution can be seen in both cross-sections 
indicating that the condition increases up to the age of 5 and then declines monotonically. The figure also documents that child obesity is more accentuated in the 2- to 8-year-olds' subgroup (averaging 14.8\%) than among their older counterparts aged 9 to $15(5 \%)$. This empirical evidence agrees with the fact that it is around the age of 6 or 7 that children start taking part in physical activity at school or in sports clubs and when children spend most of their time at school. Before that age, children are either at home with their parents or carers or/and at the nursery.

\section{[Insert Figure 1 about here]}

Given that food intake and lifestyles in children are fundamentally a parents' responsibility, this preliminary evidence might suggest an "agency failure" underpinning children's negative health outcomes. Previous studies conducted in the adult population show that obesity has risen markedly in Spain, especially among middle-aged married couples (Costa-Font and Gil, 2004). Therefore, since most children today are still being raised by married couples, it might well be that the increase in children's body mass results from the same underlying factors that explain adult obesity. In other words, parents' obesity might well be transmitted to their children via a direct influence (i.e., preparation of meals) and via the cultural transmission of eating habits learned from their parents.

\subsection{Child obesity and BMI}

The results of the probit estimation of child obesity measured using the IOTF tables (results based on the other reference tables and child overweight are available upon request) are reported in Table 2. Several econometric specifications are examined: the first three columns analyse overall obesity and the last two differentiate by gender. All estimations include controls for children's characteristics and those for their parents (see Table 1). Notice that parental obesity is controlled for in order to examine the presence of intergenerational transmission, and its effect on the socioeconomic gradient in child obesity. Statistical inference is based on clustered standard errors using the covariate region. All parameter estimates are jointly significant and the estimations show an adequate goodness of fit.

According to the first three columns, the results confirm the existence of a significant positive association between adult obesity and child obesity, confirming our vertical 
transmission hypothesis. That is, children are more likely to be obese when this condition is also prevalent among their fathers or mothers. The results indicate that the probability of having obese children is between $4.2 \%$ and $4.6 \%$ higher for obese parents. As expected, income exerts a significant negative influence on child obesity in all specifications. The probability of child obesity is roughly $3 \%$ lower as net equivalent income rises. We find that mothers with a high education background are between $1.6 \%$ and $2.2 \%$ less likely to have obese children. Interestingly, as column three shows the positive association between child obesity and a mother and a father's low educational attainment disappears once income is included in the model. As expected, mother's labour market participation is positively correlated with child obesity.

\section{[Insert Table 2 about here]}

The last two columns of Table 2 show the emergence of a differential pattern by gender. While the hypothesis of intergenerational transmission is verified for both genders, this correlation is much stronger among boys: boys (girls) aged 2-15 are roughly 6\% (2.5\%) more likely to be obese when this condition is also prevalent among their fathers and mothers. Income and mother's higher education present a significant and negative correlation with child obesity in boys only. Notwithstanding, equivalent income tends to reduce the likelihood of child obesity among girls by $2.8 \%$. Estimates in Table 2 are only marginally affected when we exclude the influence of parent obesity, suggesting that our measure of intergenerational transmission is autonomously captured by this covariate. Fairly similar results are obtained when we use the Orbegozo F. tables.

Although not shown, OLS estimations of child BMI indicate that parental BMI is significantly and positively correlated with child obesity in both genders, documenting once more a problem of agency failure. Such estimations also provide evidence of a significant negative effect of income on children obesity. Similarly, quantile regression of child BMI based on the $95^{\text {th }}$ percentile (the cut-off point generally used by experts to measure child obesity) show that these effects are much stronger for the upper deciles of the body mass distribution, clearly in line with previous studies (Ahlburg, 1998, Emanuel et al., 1992 and Classen, 2010). 
Finally, the availability of two waves allows us to test whether the parent-child obesity and BMI correlation changes over time. Although not shown, we calculated the change in the intergenerational transmission of child obesity and BMI between the 2003-04 and 2006-2007 waves by gender. Interestingly, the estimates show a marked increase in the intergenerational transmission mainly in boys. This finding is somewhat similar to the results reported by Anderson et al. (2009) who documented a substantial increase in the transmission of child obesity since the early 1970s, suggesting that shared common genetic-environmental influences have become more important in determining obesity.

\subsection{Child obesity: accounting for endogeneity and unobservables}

Table 3 reports the results for the generalised bivariate probit model estimation of child obesity and parental obesity. This strategy enables us, first, to control for the presence of unobservable characteristics influencing both outcomes and, second, to accommodate the endogenous effect of the parental obesity epidemic. We instrument parental obesity using the $\log$ of the production of milk per capita in Spain in the year in which the mother was ten years old. Again we used clustered standard errors based on 18 regions. For the sake of brevity, the table only presents the coefficients of the structural model.

The first column shows the estimation of the model accounting for the entire sample of children. As expected, we find the coefficient of the instrument to be negative and highly statistically significant. The first stage regression has reasonable explanatory power as indicated by the high value of the Wald test. The correlation coefficient for the two error terms $(\rho=-0.248)$ recognises that unobservable factors affecting both child obesity and parental obesity are negatively associated, although the low chi-square test indicates that this parameter is only significantly different from zero at $10 \%$. Interestingly, the results provide evidence of a much stronger, significant positive causal impact of parental fatness on child obesity ( 0.741 compared to 0.258 in Column 3 of Table 2), indicating a causal impact of parental lifestyles on child obesity. Here again, income and maternal higher education exert a similar significant negative influence on child obesity and a mother's labour market participation is positively correlated with child obesity. When we distinguish by gender, we find that the transmission to boys is significantly higher than transmission to girls. Results are very similar when using the other instruments. 


\section{[Insert Table 3 about here]}

\subsection{Social gradients}

To estimate the differential impact of the parental transmission hypothesis by income levels, Table 4 reports the estimates of the intergenerational transmission of child obesity across income quartiles in the two waves. Interestingly, we find the transmission to be higher among extreme quartiles, which suggests different explanations for the development of a socioeconomic gradient in child obesity.

\section{[Insert Table 4 about here]}

Figure 2 represents graphically the concentration curves of child obesity using both the IOTF and the Orbegozo F. tables. As can be seen, the graphs are well above the $45^{\circ}$ line and, thus, they clearly indicate that child obesity is unequally distributed to the disadvantage of poorer children. Interestingly, as the concentration curves for the years 2006-2007 lie above those for the years 2003-2004, the figure shows that income-related inequalities in child obesity have increased over time, regardless of the tables used to define the condition. Indeed, the degree of income-related inequality is clearly shown in Table 5, where a set of statistically significant negative CIs of child obesity is derived. Our findings indicate that according to the IOTF (Orbegozo F.) tables the CI is $-0.1034(-0.0901)$ for the years $2003-04$ while the CI is as high as $-0.1599(-0.1369)$ for 2006-2007. As such, child obesity is pro-poor distributed and has risen by roughly $50 \%$ in just three years.

\section{[Insert Figure $2 \&$ Table 5 about here]}

Finally, in Table 6 we report the decomposition of the inequality indices of child obesity into their explanatory factors (under the IOTF tables). In panel A (B) we include (exclude) parental obesity or our proxy of the intergenerational transmission of life styles. The entries in each column are derived from equation (7) and give the elasticity of child obesity and the concentration index for each regressor and the total and proportional contribution of each factor to the child obesity concentration index. The results provide evidence of the existence of a large pure income effect explaining between $72-66 \%$ of these income inequality 
estimates, even when the intergenerational transmission of life styles is accounted for. Interestingly, parental obesity explains between 6-12\% of the income-related inequality.

\section{[Insert Table 6 about here]}

\section{Conclusion}

We have examined the existence of a socioeconomic and an intergenerational gradient of child obesity drawing upon unique data from a country that has experience has significant rise in child obesity during the period 2003 to 2006. Specifically, we report empirical evidence of a significant positive association between parental intergenerational transmission of obesity and lifestyles, which is found to increase mainly among boys, which cannot be explained by genetic influences and hence calls for significant environmental effects. In addition, our results indicate that, unlike Anderson et al. (2009), child obesity not only is pro-poor distributed after controlling for intergenerational transmission but obesity has risen dramatically in just three years in Spain. These estimates are robust to different methodologies of measuring obesity in children and account for time, gender and income variability. Higher income systematically explains obesity in children and inequalities in child obesity have doubled in just three years with a pure income effect accounting for as much as $72-66 \%$ of these income inequality estimates, even when intergenerational transmission is accounted for. Although, intergenerational transmission does not appear to be gender specific, when accounted for, mother's labour market participation only explains obesity among boys but not among girls.

Overall, we offer some insights on the drivers of childhood obesity based on the existence of an intergenerational transmission of parental obesity, the effects of maternal employment as well as education that could point towards the failure of parents to cater for their children's health either owing to conflicts with work and the opportunity costs of parenting, or alternatively, the intergenerational transmission of attitudes towards food and possibly lifestyles. 


\section{References}

Abernathy, T.J., Webster, G., \& Vermeulen, M. (2002) Relationship between poverty and health among adolescents. Adolescence 37(145), 55-67.

Ahlburg, D. (1998) Intergenerational transmission of health. American Economic Review $88(2), 265-270$.

Anderson, P.M., Butcher, K.F. \& Levine P (2003) Maternal employment and overweight children. Journal of Health Economics 22(3), 477-504.

Anderson, P.M., \& Butcher, K.F. (2006) Childhood obesity: trends and potential causes. The Future of Children, 16(1), 19-45.

Anderson, P.M., Butcher, K.F., \& Schanzenbach, D.W. (2009) Childhood disadvantage and obesity: is nurture trumping nature? In J. Gruber (Ed.) The Problems of Disadvantaged Youth: An Economic Perspective. Ch. 5. National Bureau of Economic Research.

Armstrong, J.A., Dorosty, R., Reilly, J.J., et al (2003) Coexistence of social inequalities in under nutrition and obesity in preschool children: population based cross sectional study. Archives of Disease in Childhood, 88, 671-675.

Baum II, C.L., \& Ruhm, C.J. (2007) Age, socioeconomic status and obesity growth. NBER Working Paper No. 13289.

Berenson, G.S., Srinivasan, S.R., Wattigney, W.A., \& Harsha DW (1993) Obesity and cardiovascular risk in children. Annals of the New York Academy of Sciences, 699, 69-103.

Case, A.D., Lubotsky, D., \& Paxon, C. (2002) Economic status and health in childhood: the origins of the gradient. American Economic Review, 92, 1308-1334.

Case, A.D., Fertig, A. \& Paxson, C. (2005) The lasting impact of childhood health and circumstance. Journal of Health Economics, 24, 365-389.

Case, A.D., Lee, D. \& Paxon, C. (2008) The income gradient in children's health: a comment on Currie, Shields and Wheatley Price. Journal of Health Economics, 27, 801-807.

Cawley, J., \& Liu, F. (2007) Maternal employment and childhood obesity: a search for mechanisms in time use data. NBER Working Paper No. 13600.

Classen, T.J., \& Hokayem, C. (2005) Childhood influences on youth obesity. Economics and Human Biology, 3(2), 165-187.

Classen, T.J. (2010) Measures of the intergenerational transmission of body mass index between mothers and their children in the United States, 1981-2004. Economics and Human Biology, 8, 30-43.

Coate, D. (1983) The relationship between diet, parent's fatness, and obesity in children and adolescents. NBER Working Paper No. 1072. 
Cole, T.J., Bellizzi, M.C., Flegal, K.M., \& Dietz, W.H. (2000) Establishing a standard definition for child overweight and obesity worldwide: international survey. British Medical Journal, 320, 6 May 2000.

Costa-Font J., \& Gil, J. (2004) Social interactions and the contemporaneous determinants of individuals' weight. Applied Economics, 36(20), 2253-2263.

Crossman, A., Sullivan, D.A., \& Benin, M. (2006) The family environment and American's risk of obesity as young adults. Social Science \& Medicine, 63, 2255-2267.

Currie, C.E., Elton, R.B., Todd, J. \& Platt, S. (1997) Indicators of socioeconomic status for adolescents: the WHO Health Behaviour in School-aged Children Survey. Health Education Research, Theory and Practice, 12.3, 385-397. Oxford: Oxford University Press.

Currie, J., \& Madrian, B.C. (1999) Health, health insurance and the labor market. In Ashenfelter O and Card D (Eds.) Handbook of Labor Economics, Vol. 3, Part C, Chapter 50, pp. 3309-3416. North Holland, Amsterdam.

Currie, J., \& Hyson, R. (1999) Is the impact of health shocks cushioned by soc-economic status. The case of low birth weight. American Economic Review (Papers and Proceedings), $89,245-250$.

Currie, J., \& Stabile, M. (2003) Socioeconomic status and child health: why is the relationship stronger for older children? American Economic Review, 93(5), 1813-1823.

Currie, A., Shields, M.A., \& Wheatley-Price, S. (2004) Is the child health/family income gradient Universal? Evidence from England. IZA Working Paper, 1328.

Currie, A., Shields, M.A., \& Wheatley-Price, S. (2007) The child health/family income gradient. Evidence from England. Journal of Health Economics, 26(2), 213-232.

Dooley, M., \& Stewart, J. (2007) Family income, parenting styles and child behaviouralemotional outcomes. Health Economics, 16(2), 145-162.

Eisenberg, M.E., Nuemark-Sztainer, D., \& Story, M. (2003) Associations of weight-based teasing and emotional well-being among adolescents. Arch Pediatr Adolesc Med., 157, 733737.

Emanuel I., Filakti, H., Alberman, E., \& Evans, S.J. (1992) Intergenerational studies of human birthweight from the 1958 birth cohort. 1. Evidence for a multigenerational effect. $\mathrm{Br}$. J. Obstet. Gynaecol., 99, 67-74.

European Obesity Task Force (EOTF) \& European Association for the Study of Obesity Task Forces (EASOTF) 2002. The Case for Action. Position Paper, London.

Goode, A., Mavromaras, K.G., \& Smith, M. (2008) Intergenerational transmission of healthy eating behaviour and the role of household income. IZA Discussion Paper No. 3535.

Goodman, E. (1999) The role of socioeconomic status gradients in explaining differences in US adolescents' health. American Journal of Public Health, 89(10), 1522-1528. 
Gordon-Larsen, P., Adair, L.S., \& Popkin, B.M. (2003) The relationship of ethnicity, socioeconomic factors, and overweight in US adolescents. Obesity Research, 11(1), 121-129.

Gortmaker, S.L., Must, A., Perrin, J.M., Sobol, A.M., \& Dietz, W.H. (1993) Social and economic consequences of overweight in adolescence and young adulthood. New England Journal of Medicine, 329, 1008-1012.

Hoffmans, M.D., Kromhout, D., \& de Lezenne, C. (1988) The impact of body mass index of 78,612 18-year old Dutch men on 32-year mortality from all causes. Journal of Clinical Epidemiology, 41(8), 749-756.

Kawwani, N.C., Wagstaff, A., \& van Doorslaer, E. (1997) Socioeconomic inequalities in health: measurement, computation and statistical inference. Journal of Econometrics, 77(1), $87-104$.

Khanam, R., Nghiem, H.S., \& Connelly, L.B. (2009) Child health and the income gradient: Evidence from Australia. Journal of Health Economics, 28(4), 805-817.

Kinra, S., Nelder, R.P., \& Lewendon, G.J. (2000) Deprivation and childhood obesity: a cross sectional study of 20,973 children in Plymouth, United Kingdom. Journal of Epidemiology Community Health, 54,456-460.

Lake, J.K., Power, C., \& Cole, T.J. (1997) Child to adult body mass index in the 1958 British birth cohort: associations with parental obesity. Archives of Disease in Childhood, 77: 376380 .

Propper, C., Rigg, J., \& Burgess, S. (2007) Child health: evidence on the roles of family income and maternal mental health from a UK birth cohort. Health Economics, 16(11), 12451269.

Sargent, J.D., \& Blanchflower (1994) Obesity and stature in adolescence and earnings in young adulthood. Analysis of a British Birth Cohort. Arch Pediatr Adolesc Med., 148(7), 681687.

Schwimmer, J.B., Burwinkle, T.M., \& Varni, J.W. (2003) Health-related quality of life of severely obese children and adolescents. Journal of the American Medical Association, 289, 1813-1819.

Sobradillo, B., Aguirre, A., Aresti, U. et al. (2002) Curvas y Tablas de Crecimiento (Estudios Longitudinal y Transversal). Instituto de Investigación sobre el Crecimiento y Desarrollo, Fundación F. Orbegozo, Bilbao.

von Hinke Kessler Scholder, S. (2008) Maternal employment and overweight children: does timing matter? Health Economics, 17, 889-906.

Wang, Y., \& Zhang, Q.Z. (2006) Are American children and adolescents of low socioeconomic status at increased risk of obesity? Changes in the association between overweight and family income between 1971 and 2001. The American Journal of Clinical Nutrition, 84(4), 707-716. 
Whitaker, R., Wright, J., Pepe, M., Seidel, K., \& Dietz, W. (1997) Predicting obesity in young adulthood from childhood and parental obesity. The New England Journal of Medicine, 337 (13), 869-873.

Wickrama, K.A.S., Conger, R.D., Wallace, L.E., \& Glen, H.E. Jr. (1999) The intergenerational transmission of health-risk behaviors: adolescent lifestyles and gender moderating effects. Journal of Health and Social Behavior, 40, 258-272.

Wright, C., Parker, L., Lamont, D., \& Craft, A.W. (2001) Implications of childhood obesity for adult health: findings from thousand families' cohort study. British Medical Journal, 323(1), 1280-1284. 
Table 1. Definition of Variables. Pooled Sample of Children (SNHS 2003-04 \& 2006-07)

\section{Variable}

Child overweight (IOTF)

Child overweight (FO)

Child obesity (IOTF)

Child obesity (FO)

Child BMI

\section{Income}

Mother's low education

Mother's high education

Father's low education

Father's high education

Mother's labour activity

\section{Male \\ Age}

Age2

Mediterranean diet

Physical activity

Watch TV daily

Sleeping hours

Parent's obesity

Parent's BMI

Married parents

Sep./divorced parents

Note: Means are computed using sampling weights. (*) This covariate is

ts are married

assumed that they are consumed at a high frequency rate (between three times per week to a daily basis).

Dependent variables

Overweight defined according to IOTF BMI reference tables

Obesity defined according to IOTF BMI reference tables

Key explanatory variables

Log of total net equivalent income

if mother has primary or less than primary education

1 if mother has university education

1 if father has primary or less than primary education

if father has university education

Children's characteristics

1 if male

Child's age

Square of child's age

1 if follows a Mediterranean diet (*)

1 if performs physical activity in leisure time

1 if watch TV on daily basis

Number of hours slept per day

Key controls for parents

1 if the household adult parent (father or mother) is obese

BMI of the household adult parent (father o mother)

Other controls for parents
Mean

Min.

Max

Overweight defined according to F. Orbegozo BMI reference tables (percentile 85)

Obesity defined according to F. Orbegozo BMI reference tables (percentile 97)

$\begin{array}{lll}0.286 & 0 & 1 \\ 0.233 & 0 & 1 \\ 0.095 & 0 & 1 \\ 0.126 & 0 & 1\end{array}$

$\begin{array}{ll}18.22 & 6.57\end{array}$

6.568

0.311

0.204

0.312

0.185

0.611

4.262

0

0

0

0

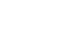

8.371

1

1

$\begin{array}{lll}0.516 & 0 & 1\end{array}$

8.828

94.09

0.053

0.783

0.904

9.440

0.124

25.26

12.77

1

58.96

$\begin{array}{lll}0.829 & 0 & 1 \\ 0.054 & 0 & 1\end{array}$


Figure 1. Childhood Obesity: IOTF reference tables (SNHS samples 2003-04 \& 2006-07)

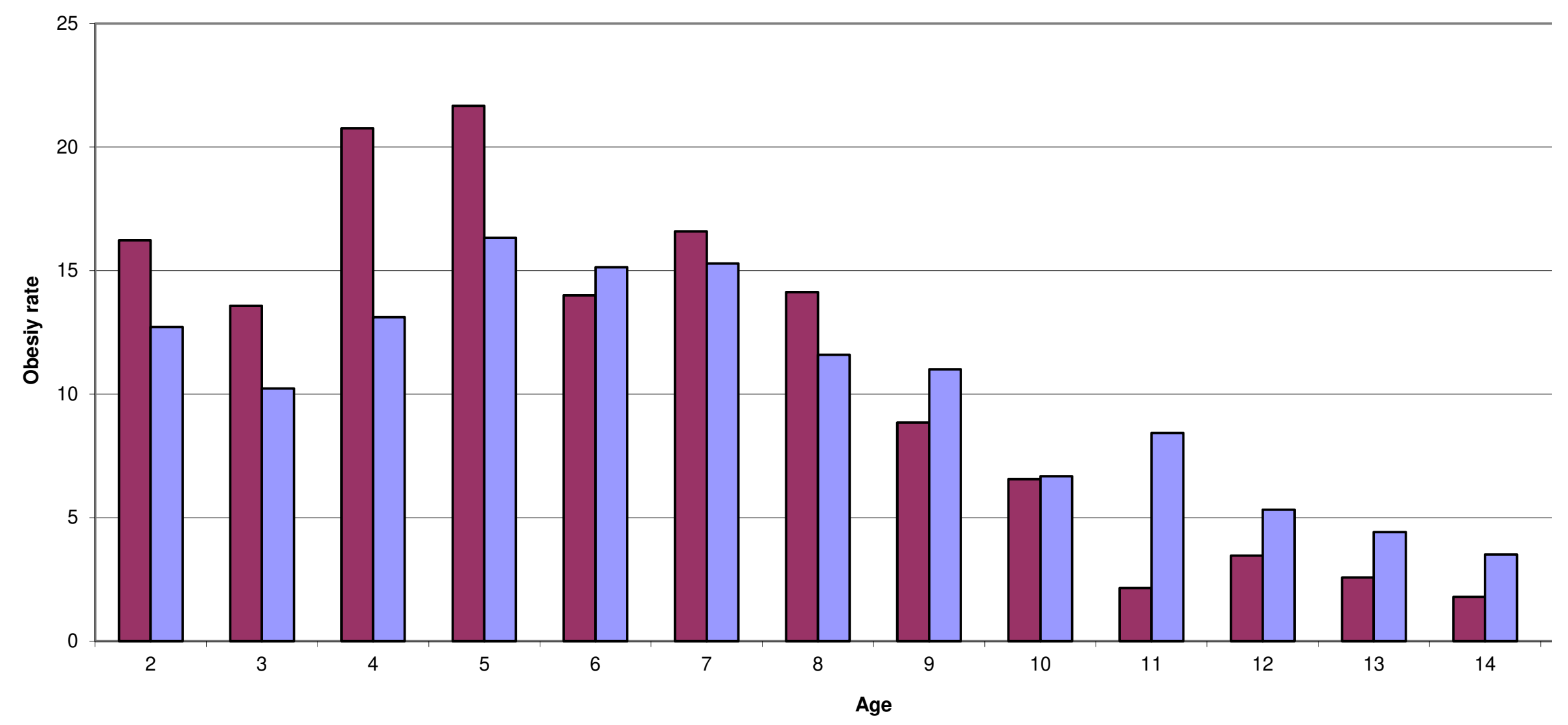


Table 2. Probit Estimation of Child Obesity. Pooled Sample of Children (SNHS 2003-04 \& 2006-07)

\begin{tabular}{|c|c|c|c|c|c|}
\hline & \multicolumn{5}{|c|}{ Dependent variable: Child Obesity (IOTF tables) } \\
\hline & $\begin{array}{c}\text { Full sample } \\
\text { Col. [1] }\end{array}$ & $\begin{array}{c}\text { Full sample } \\
\text { Col. [2] }\end{array}$ & $\begin{array}{c}\text { Full sample } \\
\text { Col. [3] }\end{array}$ & $\begin{array}{c}\text { Boys } \\
\text { Col. [4] } \\
\end{array}$ & $\begin{array}{c}\text { Girls } \\
\text { Col. [5] } \\
\end{array}$ \\
\hline Income & $-0.222 * * *[-0.032]$ & - & $-0.199 * * *[-0.029]$ & $-0.180 * * *[-0.028]$ & $-0.223 * * *[-0.028]$ \\
\hline Mother's low education & - & $0.069 * * *[0.010]$ & $0.044[0.006]$ & $0.031[0.005]$ & $0.061[0.008]$ \\
\hline Mother's high education & - & $-0.166 * * *[-0.022]$ & $-0.120 * *[-0.016]$ & $-0.166 * *[-0.024]$ & $-0.075[-0.009]$ \\
\hline Father's low education & - & $0.103 * *[0.015]$ & $0.066[0.010]$ & $0.138 *[0.022]$ & $-0.024[-0.003]$ \\
\hline Father's high education & - & $0.003[0.000]$ & $0.047[0.007]$ & $0.025[0.004]$ & $0.059[0.008]$ \\
\hline Mother's labour activity & - & $0.067 * * *[0.009]$ & $0.093 * * *[0.013]$ & $0.075^{*}[0.011]$ & $0.114[0.014]$ \\
\hline Parent's obesity & $0.267 * * *[0.044]$ & $0.282 * * *[0.046]$ & $0.258 * * *[0.042]$ & $0.315 * * *[0.057]$ & $0.178 * * *[0.025]$ \\
\hline Controls for children's charact. & YES & YES & YES & YES & YES \\
\hline Other controls for parents & YES & YES & YES & YES & YES \\
\hline Observations & 10,273 & 12,211 & 10,273 & 5,231 & 5,042 \\
\hline Wald test & $1,477.7$ & $7,244.5$ & $42,784.8$ & $5,083.5$ & $2,920.5$ \\
\hline Pseudo R-squared & 0.070 & 0.073 & 0.072 & 0.068 & 0.087 \\
\hline Obs. Pr. & 0.094 & 0.091 & 0.094 & 0.100 & 0.088 \\
\hline Pred. Pr. (\%) & $0.077(82 \%)$ & $0.074(81 \%)$ & $0.077(82 \%)$ & $0.084(84 \%)$ & $0.066(75 \%)$ \\
\hline
\end{tabular}

Note: Standard errors are adjusted for 18 clusters in region. Estimations include a dummy for the sample year. Marginal and average effects are reported in brackets. $* * * \mathrm{P}<$ $0.01, * * \mathrm{P}<0.05, * \mathrm{P}<0.10$. 
Table 3. Bivariate Probit Estimation of Child Obesity. Pooled sample of Children (SNHS 2003-04 \& 2006-2007)

\begin{tabular}{|c|c|c|c|}
\hline & \multicolumn{3}{|c|}{ Dependent variable: Child Obesity (IOTF tables) } \\
\hline & $\begin{array}{c}\text { Full sample } \\
\text { Col. [1] }\end{array}$ & $\begin{array}{c}\text { Boys } \\
\text { Col. [2] }\end{array}$ & $\begin{array}{c}\text { Girls } \\
\text { Col. [3] } \\
\end{array}$ \\
\hline Income & $-0.174 * * *[-0.016]$ & $-0.147 * * *[-0.012]$ & $-0.193 * * *[-0.013]$ \\
\hline Mother's low education & $0.030[0.004]$ & $0.0123[0.003]$ & $0.044[0.003]$ \\
\hline Mother's high education & $-0.121 * *[-0.002]$ & $-0.164 * *[-0.010]$ & $-0.077[-0.005]$ \\
\hline Father's low education & $0.046[0.006]$ & $0.106[0.010]$ & $-0.038[-0.001]$ \\
\hline Father's high education & $0.053[0.003]$ & $0.031[0.001]$ & $0.067[0.004]$ \\
\hline Mother's labour activity & $0.090 * * *[0.006]$ & $0.068 *[0.005]$ & $0.113[0.005]$ \\
\hline Parent's obesity & $0.741 * * *[0.089]$ & $0.933^{* *}[0.113]$ & $0.766^{* *}[0.072]$ \\
\hline Control for children's charact. & YES & YES & YES \\
\hline Other control for parents & YES & YES & YES \\
\hline Observations & 10,130 & 5,157 & 4,973 \\
\hline Instrument "lpmilk10" (1st stage) & $-0.262 * *$ & $-0.349 *$ & -0.205 \\
\hline Wald test (1st. stage) & 15,915 & 425.6 & - \\
\hline Rho & -0.248 & -0.318 & -0.300 \\
\hline Wald test of exogeneity & $3.017(\mathrm{p}=0.082)$ & $2.865(\mathrm{p}=0.090)$ & $2.891(\mathrm{p}=0.089)$ \\
\hline
\end{tabular}

Note: Parent's obesity is instrumented by the log of the production of milk per capita in the year in which the mother was ten years-old. Standard errors adjusted for 18 clusters in region. Marginal effects in brackets computed as $\mathrm{y}=\operatorname{Pr}($ child obesity $=1$ adult's obesity $=1$ ) at the mean values. $* * * \mathrm{P}<0.01, * * \mathrm{P}<0.05, * \mathrm{P}<0.10$. 
Table 4. Probit Estimation of Child obesity by Income Quartile. Pooled sample of Children (SNHS 2003-04 \& 2006-2007)

\begin{tabular}{|c|c|c|c|c|}
\hline & \multicolumn{4}{|c|}{ Dependent variable: Child Obesity (IOTF tables) } \\
\hline & $\begin{array}{c}\text { Quartile 1 } \\
\text { Col. [1] }\end{array}$ & $\begin{array}{c}\text { Quartile } 2 \\
\text { Col. [2] }\end{array}$ & $\begin{array}{c}\text { Quartile } 3 \\
\text { Col. [3] }\end{array}$ & $\begin{array}{c}\text { Quartile } 4 \\
\text { Col. [4] }\end{array}$ \\
\hline Parent's obesity & $0.300 * * *[0.062]$ & $0.286^{* * *}[0.051]$ & $0.038[0.005]$ & $0.379 * * *[0.050$ \\
\hline Income \& Education & YES & YES & YES & YES \\
\hline Mother's labour activity & YES & YES & YES & YES \\
\hline Controls for children's charact. & YES & YES & YES & YES \\
\hline Other controls for parents & YES & YES & YES & YES \\
\hline
\end{tabular}

Note: Standard errors are adjusted for 18 clusters in region. Estimations include a dummy for the sample year. Marginal and average effects are reported in brackets. $* * * \mathrm{P}<$ $0.01, * * \mathrm{P}<0.05, * \mathrm{P}<0.10$. 
Figure 2. Concentration Curves of Child Obesity in Spain: SNHS 2003-2004 \& 2006-2007

a) IOTF tables

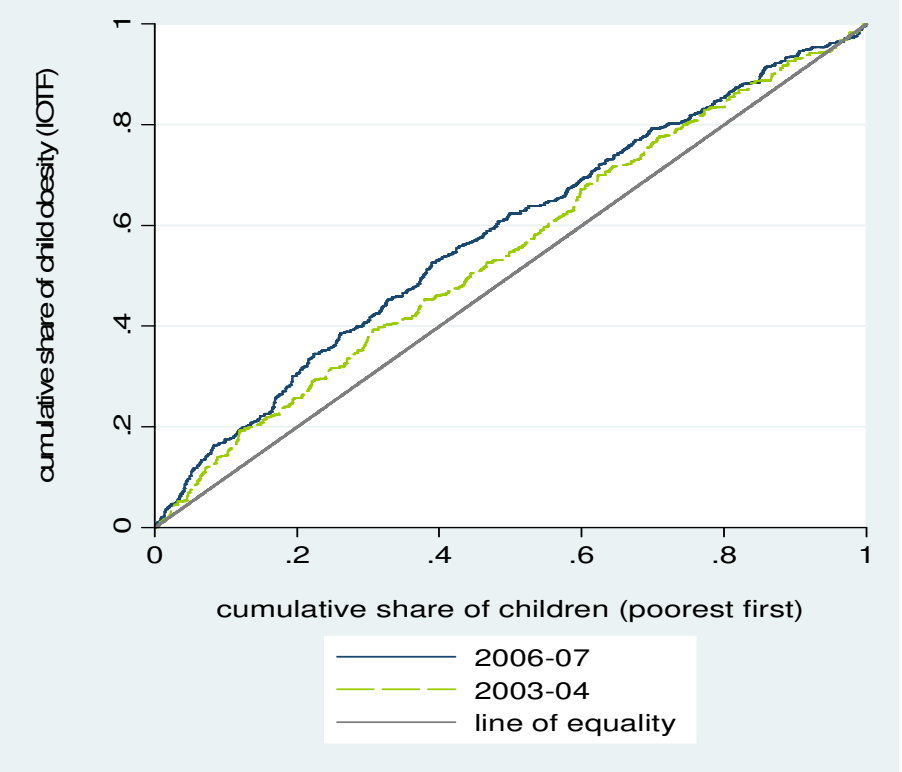

b) F. Orbegozo tables

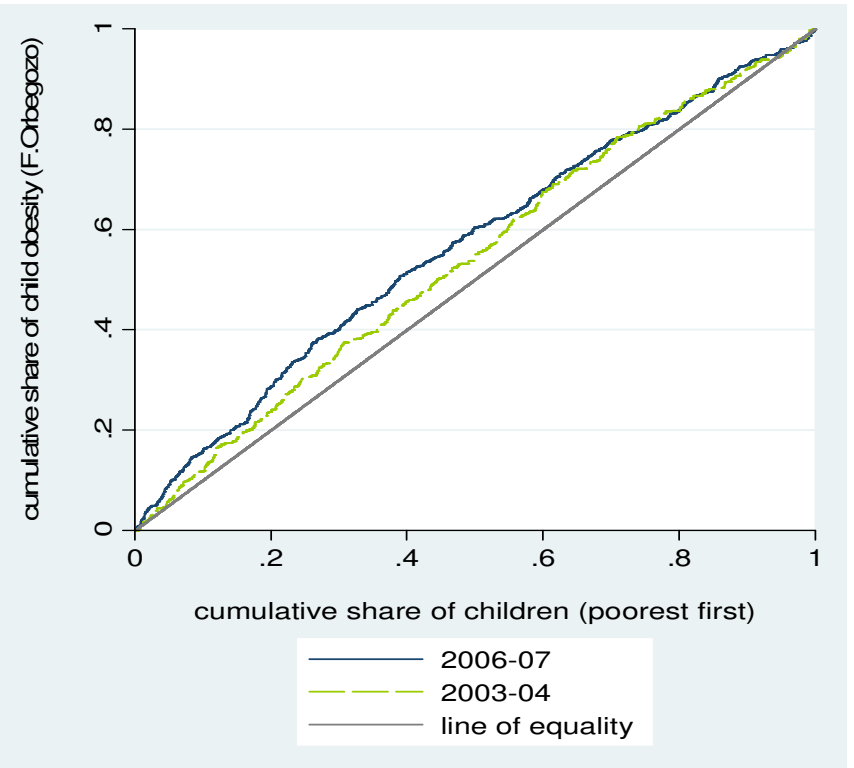


Table 5. Concentration Indices for Child Obesity: SNHS 2003-2004 \& 2006-2007

\begin{tabular}{|c|c|c|c|c|c|c|}
\hline \multirow{2}{*}{ Year 2003-2004 } & \multicolumn{3}{|c|}{ IOTF tables } & \multicolumn{3}{|c|}{ F. Orbegozo tables } \\
\hline & CI & Std. Err. & t-value & CI & Std. Err. & t-value \\
\hline Year 2006-2007 & -0.1599 & 0.0291 & -5.49 & -0.1369 & 0.0279 & -4.90 \\
\hline
\end{tabular}


tration Indices for Child Obesity in Spain (IOTF tables)

\begin{tabular}{|c|c|c|c|c|c|c|}
\hline \multicolumn{3}{|c|}{ Survey Year 2003-2004 } & \multicolumn{4}{|c|}{ Survey Year 2006-2007 } \\
\hline $\begin{array}{c}\text { Concentration } \\
\text { Index }\end{array}$ & Contr. & Percent & Elasticity & $\begin{array}{l}\text { Concentration } \\
\text { Indices }\end{array}$ & Contr. & Percent \\
\hline 0.0493 & -0.0681 & $65.9 \%$ & -2.5063 & 0.0459 & -0.1150 & $72.3 \%$ \\
\hline-0.3295 & -0.0200 & $19.3 \%$ & 0.0107 & -0.3644 & -0.0039 & $2.5 \%$ \\
\hline 0.5266 & -0.0025 & $2.4 \%$ & -0.0724 & 0.4761 & -0.0345 & $21.7 \%$ \\
\hline-0.3090 & 0.0019 & $-1.8 \%$ & 0.0221 & -0.3392 & -0.0058 & $3.6 \%$ \\
\hline 0.5542 & -0.0025 & $2.5 \%$ & 0.0328 & 0.5378 & 0.0181 & $-11.4 \%$ \\
\hline 0.1377 & -0.0039 & $3.7 \%$ & 0.0664 & 0.1315 & 0.0085 & $-5.4 \%$ \\
\hline \multirow[t]{4}{*}{-0.1666} & -0.0120 & $11.6 \%$ & 0.0565 & -0.1665 & -0.0094 & $5.9 \%$ \\
\hline & 0.0191 & $-18.5 \%$ & & & -0.0098 & $6.2 \%$ \\
\hline & -0.0154 & $14.9 \%$ & & & -0.0074 & $4.7 \%$ \\
\hline & -0.1034 & & & & -0.1592 & \\
\hline
\end{tabular}

\begin{tabular}{|c|c|c|c|c|c|c|}
\hline \multicolumn{3}{|c|}{ Survey Year 2003-2004 } & \multicolumn{4}{|c|}{ Survey Year 2006-2007 } \\
\hline $\begin{array}{c}\text { Concentration } \\
\text { Index }\end{array}$ & Contr. & Percent & Elasticity & $\begin{array}{l}\text { Concentration } \\
\text { Index }\end{array}$ & Contr. & Percent \\
\hline 0.0493 & -0.0741 & $71.7 \%$ & -2.6441 & 0.0459 & -0.1214 & $76.3 \%$ \\
\hline-0.3295 & -0.0214 & $20.7 \%$ & 0.0144 & -0.3644 & -0.0052 & $3.3 \%$ \\
\hline 0.5266 & -0.0028 & $2.7 \%$ & -0.0743 & 0.4761 & -0.0354 & $22.2 \%$ \\
\hline-0.3090 & 0.0000 & $-0.03 \%$ & 0.0221 & -0.3392 & -0.0075 & $4.7 \%$ \\
\hline 0.5542 & -0.0032 & $3.1 \%$ & 0.0328 & 0.5378 & 0.0176 & $-11.1 \%$ \\
\hline \multirow[t]{3}{*}{0.1377} & -0.0055 & $5.3 \%$ & 0.0664 & 0.1315 & 0.0087 & $-5.5 \%$ \\
\hline & 0.0190 & $-18.4 \%$ & & & -0.002 & $5.8 \%$ \\
\hline & -0.0155 & $15 . \%$ & & & -0.0069 & $4.3 \%$ \\
\hline
\end{tabular}


${ }^{1}$ This is in contrast with the US where it appears to be driven by higher socio-economic groups (Anderson et al., 2003).

${ }^{2}$ Interestingly, they find that an additional year of maternal education reduces child body mass index (BMI) by an average of $0.2 \mathrm{~kg} / \mathrm{m}^{2}$.

${ }^{3}$ However, the exact sources affecting the transmission of an individual's health behaviour are contentious. Generally, intergenerational transmission is measured by examining the correlation between children's and parents health. If the overall correlation has increased over time, this suggests that something in the common environment (or related to the decisions made by the family) is affecting all family members. On the other hand, if the correlation has decreased over time, then this suggests a larger role for something unique to the environment those children - but not their parents - face, for example something present in child care settings or public schools 